\title{
Strategic Corporate Communications
}

\author{
Vineet Kaul \\ Research Scholar, DA-IICT University (Dhirubhai Ambani Institute of \\ Information, Communication \& Technology), Gandhinagar, Gujarat
}

\section{ABSTRACT}

During the last decade Strategic communication has emerged as a global field of communication research. Scholars are locked in intense debate on the deliberate purposive use of communication since there is no common understanding to answer what is the core prospective and benefits of strategic communication. Despite these forms of institutionalization, there is still no universal understanding of the pillars on which the field rests. What are the core perspectives and benefits of strategic communication? Are we using appropriate conceptualizations of communication and strategy? How does it differ from traditional disciplines? What is the extra value of an integrated view? What can we learn from recent debates in strategic management and strategic alignment? What is the extra value of an integrated view? What are the methodological challenges of researching the link between communication and organizational goals? What are the experiences from building strategic communication programs at universities in different countries? What are specific challenges of international and comparative research in strategic communication? How can empirical studies inform the debate? How is the field developing in different parts of the world? What do we know about the job market, and how can educators prepare students for the occupational field? Last but not least what do we know about the job market, and how can educators prepare students for the occupational field?

This article examines the nature of strategic communication, which is defined as the purposeful use of communication by an organization to fulfill its mission. To be successful in today's business environment, companies need to integrate their communication efforts. Companies today have more arrows in their communication quivers than ever before to get their messages across to varied internal and external constituencies. Why then do companies' communications still miss their mark? With an integrated communication function, companies can respect different constituency viewpoints, concern, and "hot buttons" while still ensuring consistency in message content.

Today's constantly changing and fast paced global business environment Corporate communication has become more and more strategy oriented The interest in communication in organizations, especially in internationally operating companies is greater than ever. Communication is increasingly considered an integral part of business knowhow (e.g. Charles, 2009) and an essential business tool, as well as a strategic tool of senior management of global companies (Hämäläinen \& Maula, 2004).

This paper examines how communicating a corporate strategy is critical to an organization's success at all levels. Covers the importance of communicating corporate and marketing strategies to employees, investors and other stakeholders. Explores how to set communication objectives that reflect the business plan, how to ensure that communications strategy reinforces business strategy, and how to evaluate the effectiveness of corporate communications. The main question is answered by posing three sub-questions: How is communication involved in strategy work? What are the main benefits and challenges of the 
communication function in strategy work? And how does the CEO see him/herself as a communicator of the corporate strategy?

Keywords: International business communication, corporate communication, CEO, Strategy, Management, Management communication

\section{INTRODUCTION}

The field of public relations and strategic communication has faced radical changes in recent years due to the 21 st century digital revolution. In this dynamic and sophisticated market corporate communications or public relations (PR) have become recognized as an increasingly important function in business organisations. It has matured into a key discipline and has play total business system. (Winner, 1993). This raises questions as to "How prominent and strategic has the role of communication become in the governance of complex organizations, both private and public? To what extent is the communication called upon to participate in, and support strategic decisions at corporate and business levels? Is communication able to offer a meaningful contribution to the decisions made in the most established business areas such as finance, marketing and production? Does it make sense to speak about a communication-oriented organization, or rather an organization in which communication helps to guide and influence all major decision making processes?" In other words, is strategic communication taking over? Companies today have more arrows in their communication quivers than ever before to get their messages across to varied internal and external constituencies. Why then do companies' communications still miss their mark? Although much has been written but no empirical research is found on the role and task.. To be successful in today's business environment, companies need to integrate their communication efforts. Companies with numerous and far-flung operating divisions — essentially "organizations within organizations" — often require coordinated communications efforts to get employees within individual operating companies to even consider how they fit into the greater organization. And to that end, sophisticated, well-versed businesspeople who can speak the language need to be the ones crafting the messages and communicating."
In this environment, the old adage that 'A lie can be halfway around the world before the truth has its boots on' becomes doubly true with today's technologies...the longer it takes to put a strategic communication framework into place, the more we can be certain that the vacuum will be filled by the enemy and by news informers that most assuredly will not paint an accurate picture of what is actually taking place." An organization's reputation is only as good as its corporate communications strategy. As the chief architects of our companies' messages, we must stay abreast of emerging trends - changing market and workplace demographics, global business conditions, new media applications - while helping our leaders recognize the strategic communications issues embedded in corporate growth plans. The dominant world view of corporate communication is the asymmetrical view that corporate communication is a way of getting what an organisation wants without changing its behaviour or reaching a compromise with its stakeholders or publics. This mindset guides organisations in directions that are ineffective and not in their long-term interests. Asymmetrical world views steer corporate communication practitioners towards actions that are unethical, socially irresponsible and ineffective. Such practitioners presuppose that the organization knows best and that stakeholders/ publics benefit from 'co-operating' with it (Grunig, 1989).

Corporate communications and public relations professionals are currently forced into a position where they need to balance the hectic business landscape with the fast pace communication that takes place between the organisation and its consumers. Today, corporate communication initiatives are no longer just about getting the message across; but rather being actively involved in engaging, managing, tweaking and constantly securing the various organisational communication lines, both internally and externally! In order to understand how radical changes in business and the media have influence the practice of corporate communication, we need to look first at those changes themselves. The field of corporate communication has developed to a large extent since its first inception in the mid-90s. Corporate communication began as what many of us recognize as Public Relations (PR). The function of earlier PR departments was focused on preventing media from getting too close to management. Argenti argues that "the first PR professional were asked to 
protect the company from bad publicity, often by 'spinning' damaging news in a positive light." This idea became popular through the 1960s; however, organizations soon found that external communication was not the only solution to their communication problems. Within an enterprises' business organisation, corporate communication is frequently split between the functions marketing and communication. The complexity of corporate communication and the lack of a clear, widely accepted definition for both seem to decrease effectiveness and efficiency with reference to achievements. Often both functions present a situation of rivalry instead of collaboration and clearly assigned structures, which, it is assumed, is fuelled additionally by questions of power within organisations.

Very little systematic research has reviewed the applicability of strategic management concepts including SWOT (strengths, weaknesses, opportunities and threats) analysis, industrial organisation (I/O), resource-based view (RBV), knowledge-based view (KBV), balanced scorecard (BSC) and intellectual capital (IC).The term "strategic communications" has become popular over the last two decades. It means infusing communications efforts with an agenda and a master plan. Typically, that master plan involves promoting the brand of an organization, urging people to do specific actions, or advocating particular legislation. Strategic management theory differentiates between enterprise, corporate, business-unit, functional and operational strategy. With reference to these strategy levels, corporate communication strategy is conceptualised as a functional strategy, providing focus and direction to the corporate communication function. Acting as a framework for the communication plans developed to implement the strategy, it makes the corporate communication function relevant in the strategic management process by providing the link between the organisational mission and communication plans. Corporate communication strategy is seen to be the outcome of a strategic thinking process by senior communicators and top managers taking strategic decisions with regard to the identification and management of, and communication with, strategic stakeholders (Steyn 2000a). The body of knowledge in the field of corporate communication indicates a strategic role for the corporate communication manager. However, there are but a few references to corporate communication 'strategy' in a strategic organisational context. Few practitioners seem to understand the meaning of strategy, although it is a known, uncomplicated concept to those familiar with management theory. The key problem seems to lie in the application of strategy for corporate communication (public relations) issues. It is therefore the aim of this article to explain the meaning of in a corporate communication context. Based on the strategic management Literature, corporate communication strategy is conceptualised as a strategy, providing focus and direction to the corporate communication function. It is differentiated from strategy as it is known in the communication plan - the latter being the approach to communication activities. Corporate communication strategy is proposed as providing the missing link between the corporate strategy and the corporate communication function.

\section{A STRATEGIC WEAPON}

In a battle for overall international competitive advantage, corporate communication can prove to be a crucial strategic weapon. Strategy is a concept, an abstraction, a theory of the business, often inferred by reviewing a pattern of managerial decisions. Structure is real, an artifact, a visible determinant of the practice of business, often designed to orient, limit and motivate managerial decision making. That strategy drives structure is a long-accepted tenet deriving from Chandler's (1962) seminal, historical analysis. That structure in turn creates strategy is increasingly recognised but not as well understood. Adhocracies (Mintzberg, 1979), bureaucracies (Weber, 1947) and clusters (Mills, 1991) are instances of vastly different forms of organisation that not only reflect but effectively create very different strategies. At the extreme, the argument can be made that structure is strategy.

As corporate strategy has evolved in sophistication, reliance on strategic communication should have become more fundamental--yet too often communication is nearly completely overlooked as anything more than window dressing. Truly strategic communications can be an ongoing input into the corporate strategy and indispensable to its execution. Corporate strategy aiming to be transformational needs the communication strategy to be a dynamic driver, helping to propel the business to a higher plane. New media, social integration, changing demographics, 
shifting corporate cultures, global challenges, the constant need to stay ahead and on top-all of these factors are driving a massive shift in how organizations communicate to each and every audience - from employees to communities to the world at large The chief communication executive at a Fortune 500 multinational corporation today faces the challenges of a rapidly changing the size and scale of global corporations, institutions and interconnected business environment posing new challenges and opportunities, the hyper-connected communication environment which has created relationships, challenges and opportunities that never existed before and a substantially transformed understanding of what a $21^{\text {st }}$ century corporation stands for.. Gone are the days when time was a commodity. There is little time to prepare the latest CEO speech, the CFO's financial report or the latest corporate press release. The company's employees, shareholders, the media, governments and, most important, the customers are more impatient than ever - they want to hear the latest official company response to the company news of the moment, whatever it may be, whether financial results, a merger or acquisition, new product release, safety recall, competitors' actions, executive misconduct.

Strategic Corporate Communication refers to communicating a concept, a process, or data that satisfies a long term strategic goal of an organization. The link between strategy and its implementation has always been tenuous. Developing an integrated, strategic approach to communications is critical to success. There is a widespread belief in the professional world that in today's society the future of any one company depends critically on how it is viewed by key stakeholders such as shareholders and investors, customers and consumers, employees, and members of the community in which the company resides. Public activism and globalization have further strengthened this belief; and have also brought the importance of strategic communications management into closer orbit. Not surprisingly, therefore, both the academic and professional worlds have been suggesting frameworks and models that prescribe steps towards the 'strategic' use of communications including such ideas as 'integrated marketing communications', 'corporate identity management', 'reputation management', 'stakeholder communications' and 'excellent public relations'. Organisations today need to plan their communication systems to ensure up-to date information; knowledge and awareness are always available to all who need them. A strategic corporate communication is the outcome of a strategic thinking process where senior communicators and managers take strategic decisions to identify and manage corporate communications and communicate them to stakeholders. With or without a formal communication strategy, every organisation communicates with its audience in one way or another. However, to ensure effective relationships with key stakeholders, every corporate organisation requires a dynamic plan that allows it to strategically relate with its customers as well as other key internal and external stakeholders.

Nowadays communication professional are facing lot of challenges in the areas of global corporate and brand positioning, internal relations in change situations, corporate identity shaping, and brand management. All communication is based on organizational strategy and the communication professionals are expected to fulfill the objectives of the organization. Communication can become strategic weapon for organisational effectiveness as it is the basis for maintaining pace and of ensuring that change can happen at all levels. It is through the management of sound and coordinated systems of communication that an organisation can integrate its various parts to ensure workforce harmonisation and achieve awareness of its performance. Effective corporate communication is closely related to the success of the organisation. An organization's reputation, survival and success rests on its ability to communicate with the public as well as its own employees and stakeholders. When effective corporate communications strategies are incorporated into a business structure, regardless of the size of the organisation, the ability to achieve global communication will be strengthened.

Corporate communication is closely linked to business objectives and strategies. It is the processes an organisation uses to communicate all its messages to key stakeholders. It encodes and promotes a strong corporate culture, a coherent corporate identity, an appropriate and professional relationship with the media, and quick, responsible ways of communicating in a crisis. It is essential if organisations are to inform and influence external stakeholders, including their customers, and harness the efforts of all internal stakeholders towards the successful accomplishment of organisational objectives. 


\section{BUSINESS AND COMMUNICATION}

Successful businesses rely on clear communication. Effective internal communication has a synergistic, positive effect, bringing benefits in employee satisfaction and correlating with higher market and financial performance. Companies that have mastered the art know that effective communication must be rooted in interactive dialogue rather than a top-down monologue if it is to have an impact beyond the content of each corporate message.There has been increased anxiety among chief communications in companies in response to changing business models and spread of network enterprise that requires deep understanding of business strategy to develop articulate ideas to persuade others to achieve business goals. The trend has required companies to accomplish and deliver more with limited resources to leverage business expertise and media flux to add strategic advantage and value. The role of corporate communication has evolved and has begun demonstrating strategic understanding of rapidly changing business environment by building positive relationships. Communications executive are in charge for reputational management and are increasingly involved on investor's relations and the development to annual report as a significant role in disclosure, transparency and as a commitment to accountability to the organisation. Corporate communication has become integral part of change informing and providing counsel as strategy is put into place due to the broadening culture of driving internal business towards better communication.

As a new industrial superpower, India is changing the way business is being conducted around the globe. This creates a complex challenge for communication directors, HR executives, and marketing departments who must develop effective corporate communication strategies tailored to the unique sensibilities of the Indian people - whether they are employees, possible customers, or prospective investors. With the evolving market trends, there has been a growing integration of marketing and corporate communication especially with the growing importance of social media and other forms of unpaid media. Corporate communication and media relations is no longer confined within the organisation but need to be addresses to various constituents to not only earn stakeholders trust to build public image and reputation for long term survival / sustainability but to analyse the interdependence of strategy and communications in getting a strategy right and bringing it to a successful result

Theoretically supported corporate communications are effective in the successful business and its effects identified by the leading companies. Today's constantly changing and fast paced global business environment has strengthened the status of communication. The interest in communication in organizations, especially in internationally operating companies is greater than ever. Communication is increasingly considered an integral part of business knowhow (e.g. Charles, 2009) and an essential business tool, as well as a strategic tool of senior management of global companies (Hämäläinen \& Maula, 2004).

This constant change and especially the economic downturn throughout the world have created a situation where strategic communication is one of the key factors of success. Kameda (2005), believe that since the world is becoming increasingly globalized, international business communication is more significant for companies than ever. He argues that there is a large difference between domestic business transactions and international transactions. According to Argenti (2003, p. 37) a growing number of organizations recognize the value of communication and more and more money and time is spent accordingly. It can be argued that even the best strategy is useless if its implementation fails (e.g. Argenti, 2003; Juholin, 2001; Walker, 2006; Hämäläinen \& Maula, 2004).

Global business settings create the international business environment where companies are operating. To remain competitive organizations are forced to be flexible and to be able to quickly adapt to the changes in their global environment. According to Walker (2006), instead of emphasizing planning, organizing and coordinating, the focus has moved to communication. International business communication and its role in the changing international workplace have become more established.

\section{STRATEGY AND VALUES}

Corporate values are sets of real beliefs that determine standards of practices. The concept of 'strategy' are well-known in management theory and practice. However, the concept of 'corporate communication 
strategy' has received little attention in the public relations (corporate communication) body of knowledge. There is mention of a strategic role for the corporate communication practitioner, but few explanations or descriptions of what corporate communication strategy means in a strategic organisational context. Van Riel (1995:142) is of the opinion that academic knowledge with regard to the strategic management of an organisation's communication is relatively limited. Strategy could be seen as the thinking, i.e. the logic behind the actions (Robert, 1997:22). Drucker (in Kotler, 1988:61) sees it as an indication of an organisation's positioning for the future, deciding what should be done rather than how it should be done. Strategy requires choices-deciding what particular kind of value an organization wants to deliver and to whom (Porter, in Gibson, 1997).

The link between strategy and its implementation has always been tenuous. Top consulting companies have employed countless MBAs to develop strategy for their clients. Academics at top B-schools have spent their careers developing frameworks explaining how to develop better strategies for top companies. However, only a handful of academics and a cadre of tactical consultants, primarily public relations companies, have struggled with strategy implementation in the area where it matters most: its communication to a set of varied constituents. Many companies take a tactical short term approach to communicating with key constituents, which is not only nonstrategic but may be inconsistent with the corporate strategy or even impede it.

We define strategic communication aligned with the company's overall strategy, to enhance its strategic positioning when companies take a strategic approach to communication; communication becomes integral to the formulation and implementation of strategy. Researchers have found that the companies most likely to recognize the strategic communication imperative are those in which the CEO has an inherent understanding of how communication can be differentiator for a business and thus can drive strategy.

Strategic communications means using corporate or institutional communications to create, strengthen or preserve, among key audiences, opinion favourable to the attainment of institutional/corporate goals. The concept of 'strategy' is well-known in management theory and practice. However, the concept of 'corporate communication strategy' has received little attention in the public relations (corporate communication) body of knowledge. There is mention of a strategic role for the corporate communication practitioner, but few explanations or descriptions of what corporate communication strategy means in a strategic organisational context. Van Riel (1995:142) is of the opinion that academic knowledge with regard to the strategic management of an organisation's communication is relatively limited. Although the corporate communication industry acknowledges that strategy should be an integral part of its communication programmes, few practitioners seem to understand the meaning of strategy.

"Strategy and the communications world, and particularly the PR part of that world, just do not seem to go together. It is certainly unusual to come across a memorable, cogent, sustained, and effective communications strategy. Not a brand strategy. Not a marketing strategy. Not an advertising strategy a communication strategy" (Tibble 1997:356).

Steyn and Puth's concept of five levels of communication strategy proposes Business Strategy as the third, marketing oriented layer (2002). This is supported by Grant and Schlesinger's "valueexchange", (cited in S. Oliver 2007, 34). Communication theory suggests further dimensions: perception (e.g., reputation and image), positioning and relationships as organisational value drivers. By communication of inherited values, an organisation gives sense to its economic activities (Westphalen 2004, 67). Therefore it is concluded that corporate communication can increase values beyond markets, implying that messages are changing from economic enterprise-structure to enterprise-structure (DemontLugol, Kempf et al. 2008, 322).

Taking a more global perspective on a firm's interactions with its audiences and with reference to an increasing emphasis on intangible values, the question is, whether separation of marketing and communication and frequent inter-organisational rivalry can be beneficial. More and more it is acknowledged that, for a strategy-focused organisation, departmental restrictions result in less appropriate answers for the corporate context, which Johnson Scholes and Whittington describe as increasingly complex, being of changing environments and needs appropriate configuration of resources and capabilities to meet demanding markets 
and to fulfil stakeholder expectations $(2009,3,105-$ 110).

The discussion about interdepartmental taskforces goes beyond the field of communication, but gains even more importance for these disciplines being so closely connected. Corporate communication has developed many subareas. Among these marketing communications, shareholder and internal communication are the most frequently discussed. But research has detected that companies need to address more than a few selected groups of their environment, specifically within their permanent struggle for survival, which brought the stakeholder concept and its relevant communication onto the organisational agenda. The complexity of different expectations, which different audiences have, requests strategy, structure and the organisation of messages, and the multitude of channels and media need to be managed, demanding skills, management and integration. One option is integrated communication, which Hofbauer and Hohenleitner $(2005,119)$ describe as the strategic and operational alignment of all communicative ruling principles for the achievement of a consistent perception by all relevant target groups. Further, little doubt exists that ICT innovations offer new opportunities and challenges of increased complexity requesting multichannel communication. MacLuhan's "the medium is the message" gains a new extended meaning (cited in Harvey 2002, 37-44). To deal with such complexity, which multiple stakeholder expectations represent, to which adds an increased media landscape and which is suffering from a missing widely accepted definition and understanding, it is suggested that this represents an increasing handicap for the achievement of added value, when marketing and communication are separate organisational functions.

\section{DEVELOPING A COMMUNICATION STRATEGY}

The strategic approach to communications and dissemination is relatively straightforward. Developing a good plan that powerfully connects your objectives with a dynamic set of messages and vehicles is harder. And creating a good plan you can actually execute against is even harder. The concept of Communication strategy is based on the assumption that corporate communication/ public relations/ communication management is practiced as a strategic management function; that it assists the organisation to adapt to its environment by achieving a balance between commercial imperatives and socially acceptable behaviour; that it identifies and manages issues and stakeholders to ensure that organisational and communication goals are aligned to societal and stakeholder values and norms; and that it builds relationships through communication with those on whom the organisation depends to meet its economic and socio-political goals.

Drawing up a communications strategy is an art, not a science and there are lots of different ways of approaching the task. Communication strategy is conceptualised as a functional strategy, providing focus and direction to the Communication function. It is facilitated by a practitioner performing the role of the communication manager at the functional organisational level. It is the outcome of a strategic thinking process by senior communication practitioners and top managers, taking strategic decisions on the management of, and the communication with, strategic stakeholders. Developing Communication strategy makes the Communication function relevant in the strategic management process by providing the link between the organisation's strategic goals and its communication plans.

Your objectives are the key to the success of your communications strategy. They should ensure that your communications strategy is organisationally driven rather than communications driven. Your communications activity is not an end in itself but should serve and hence be aligned with your organisational objectives. The Communication strategy development process can be summarised as including both the formulation of communication goals in the Communication function's 'deliberate' strategy development (typically as part of the budgeting cycle, for example once a year), as well as the ongoing formulation of communication goals as part of 'emergent' strategy development (the latter resulting from environmental scanning and issues management).

The Communication strategy formulation process consists of several steps:

\section{Step 1: Develop 'deliberate' communication goals.}

The organisation's key (strategic) priorities are reviewed, culminating in a series of communication 
International Journal of Trend in Scientific Research and Development (IJTSRD) ISSN: 2456-6470

goals and themes aligned

these priorities, representing 'deliberate'

Communication strategy. The communication goals focus on closing the vision - culture - reputation gaps, thereby increasing the effectiveness of the Communication function.

\section{Step 2: Set efficiency targets.}

These are set to supplement communication goals, thereby increasing the efficiency of the Communication function.

\section{Step 3: Develop 'emergent' communication goals.}

Constantly emerging societal and stakeholder issues that are identified in the organisation's issues and stakeholder management process are addressed in a series of communication goals and themes that represent 'emergent' Communication strategy. The communication goals focus on closing the vision - culture - reputation gaps, thereby increasing the effectiveness of the Communication function.

Step 4: Develop a communication framework. Strategy development is transformed into strategy implementation by means of the communication framework. The latter provides an opportunity to indicate which communication plans will be developed around each of the goals.

\section{Step 5: Set communication budgets.}

The communication framework is resourced by deploying a budget.

\section{Step 6: Set evaluation methodology.}

The measurement of delivery on communication goals and efficiency targets are planned here.

\section{Step 7: Generate communication plans.}

Properties defined in the Communication strategy for each of the intended Communication plans (e.g. descriptions, communication goals, planning horizons, and responsible people) will feed automatically through to the new Communication plans.

Why develop communication strategies? The effective communication of corporate strategy may help a company build strategic credibility. Strategic credibility should be based on a positive stakeholder's view of the company's overall corporate strategy, performance and its strategic planning processes. Does the firm's strategy make sense? Is it understandable and believable? Is it responsive to emerging opportunities in the environment and sensitive to the internal strengths of the firm? Does the company have an effective planning process that enhances the probability of a continuing stream of sound, strategic decisions? The company that can answer these questions affirmatively, and, perhaps more important, communicate its answers effectively, can establish and reinforce its strategic credibility among key stakeholders. To be effective, it has to be a live working document and should reflect the fact that communicating is a cross-cutting issue that affects the whole council. Individual departments should not be operating their own communications in isolation.

A solid corporate communications strategy helps organizations effectively communicate with internal and external stakeholders, including employees, vendors, customers and the public at large. When done effectively, it streamlines communications among business functions, helping management, human resources and marketing maintain a unified voice and consistent messages. Developing a solid corporate communications strategy can help a business thrive by preventing the costly mistakes that inevitably result from miscommunication.

The corporate communication strategy must be owned internally, from the top of the organisation to the front line staff, if it is to be implemented effectively and receive the resources it needs. There is no single format for putting together a communication strategy, but good ones tend to:

$>$ engage relevant external stakeholders

$>$ use consultation and research to provide a baseline

$>$ set measurable objectives

$>$ establish clear indicators

$>$ gain buy-in of senior managers, particularly where responsibility for some of the objectives and actions falls to them, for example on recycling targets or promoting community engagement.

The author regards corporate communication strategy as a functional strategy, providing the focus and direction for an organisation's communication with its stakeholders - determining what should be 
communicated to assist in achieving organisational goals. It is an approach that directs the course of action of the corporate communication function and provides an indication of its positioning for the future. It $\mathrm{i} s$ the thinking, i.e. the logic behind the corporate communication function's activities, the rather than the how - the mechanism that leads the function towards effectiveness (doing the right things), rather than towards efficiency (doing things right). Corporate communication strategy is a pattern in the corporate communication function's important communication decisions and actions regarding relationships with strategic stakeholders, stated in such a way that the attitude of the organization towards its stakeholders is clear. It is developed within the context of the organisation's vision, mission, corporate culture, policies and strategies (the internal environment), but focuses on an assessment of the external (macro and task) environment, and on the stakeholder environment.

\section{Communication In Business Context From Strategic Perspective}

A communication strategy is a single, coherent narrative that describes a communications solution to a problem or bundle of problems. Corporations are changing; they are reinventing, rethinking, transforming, and reengineering themselves. The forces affecting corporate communication, marketing, and advertising, five general categories of forces have emerged: a new sophistication in customers or audience; new media and technologies or communication tools; a more complex ethical environment; stronger economic factors; and new strategic alliances. Effective corporate communication takes into account the need to capitalise on the psychology of its publics, the best mix of communication channels to suit them and minimises the likelihood of a crisis. It can also add a positive ethical layering to the organisation. There is a strong link between communication management and strategic planning. The two should, ideally, be inseparable because communication needs to be a core organisational value which can effect change and sustain the company's vitality.

Corporate communication must add significant value and be aligned with organizational goals. In this way there is a culture of shared understanding rather than a culture of elaborate rules. Employees feel Article Reputation Management and Strategic Communications Planning involved and appreciated and behave as 'ambassadors of goodwill', to external publics.

Identifying your publics in planning and evaluating programmes for strategic communication (including reputation management) it is important to identify and assess those publics which can have an influence, for good or bad, on the company. Your company does not have a single image or reputation - everyone who comes into contact with it has differing information and experiences and so differing perceptions. It is the publics who form the reputations of the company, not the company itself. Stakeholders (publics) fall into three main groups: normative, functional and diffused. Normatives include shareholders, the board, professional associations, government and provide authority and set rules. Often limits are set on the scope and conduct of the company's operations. The board of directors and the shareholders has considerable influence on what management decisions may ted.

The first step toward truly strategic communications is to align integrated communications objectives and plans with the corporate strategy. The focus of communications efforts--internal communications, marketing communications and media relations (including social media)--should match the focus of annual and longer-term business plans. The corporate operating committee should view communications as a vital function for executing these business plans. In fact, the business should view its communications function as a critical competitive advantage. Too often, it does not.

As corporate strategy has evolved in sophistication, reliance communication should have become more fundamental--yet too often communication is nearly completely overlooked as anything more than window dressing.

Communications within an organization is something that most of practitioners see as essential and vital, but only a few business people truly understand its role (Argenti \& Forman 2002). Many researchers (see Argenti, 2003; Louhiala-Salminen, 1999, 2009; Kalla, 2006; Miller, 1996.) propose that communication in the business context can be divided into four different areas: organizational communication, management communication, corporate communication and business communication. Each of these communication areas have certain unique features and 
have somewhat different perspectives on communication in the business context. Consequently, there exists a wide variety of definitions to terms used on communication in the organizational context. In what follows, four communication areas are briefly described.

Organizational communication has been defined as a discipline that concentrates on the context in which communication occurs and on how the context organizational can affect communication processes (Walker, 2006; Louhiala-Salminen, 2009). Management communication refers to communication between a manager and employees (e.g. Cornelissen, 2008 p. 196), and as a discipline according to Lamar Reinsch. Jr (2009, p. 279), management communication concentrates on understandingand improving the communicative behavior in the managerial context. Whereas, Åberg (2006, p. 93), defines communication of management to be management work in organizations, in which the following elements are emphasized: interpretation, producing and distributing the information, interaction along with motivating and encouraging of the employees.

\section{Top-Management and Communication \\ Strategy}

In today's ever-changing business environment, communicators face the complex challenges of developing techniques and processes to manage information in ways that enhance the knowledge and intellectual capital of their organizations. Communicators and senior management must work together to establish proactive, well-defined communications strategies — that engage the workforce and support the organization's business goals. A close tie between business and communications strategies aligns the workforce with the direction and movement of the organization, encourages proactive input and allows for more accurate measurement of organizational practices.

Reinsch (2009) suggests that top level managers spend a lot of their time communicating, sometimes as much as 90 per cent of the workday, using multiple media, both inside and outside of the company. However, individual managers' communication practices vary a lot. Many researchers have suggested that managerial work consists of the following functions: planning, organizing, coordinating and controlling (Johnson et al., 2009; Reinsch, 2009). According to Suominen \& Karkulehto \& Sipponen \& Hämäläinen (2009, p. 14), managers affects to the interpretation of the strategy whether they intend it or not. Therefore they present that managers need to be aware of their role in strategy work.

Successful management requires downward communication to subordinates, upward communication to superiors, and horizontal communication to peers in other divisions. Getting a task done, perhaps through delegation, is just one aspect of the manager's job. Obtaining the resources to do that job, letting others know what is going on, and coordinating with others are also crucial skills. These skills keep the organization working, and enhance the visibility of the manager and her division, thus ensuring continued support and promotion.

Downward communication is more than passing on information to subordinates. It may involve effectively managing the tone of the message, as well as showing skill in delegation to ensure the job is done effectively by the right person. In upward communication, tone is even more crucial, as are timing, strategy, and audience adaptation. In neither case can the manager operate on automatic as the messages are sent out.

According to Steyn (2003) strategic management is defined as a continuous process of thinking through the current mission of the organization, thinking through the current environmental conditions, and then combining these elements by setting forth a guide for tomorrow's decisions and results. Whereas Frigo \& Litman (2001), argue that strategic management can be described to have two powerful pillars of management thought and activity, one of business strategy and one of business execution Reinsch (2009, p. 279) on the other hand argues that management communication performance and individual achievements of the current manager. Argenti (2007, p169) argue that CEO, CFO and individuals for company's IR need to work closely together.

Quirke (2010), has indicated four leader types in terms of communication: 1. Director, one that gives a clear sense of direction. 2. Visionary, an enthusiastic leader who has unspecific vision. 3. Empathizer, leaders who can "feel the pain" of their people. 4. 
Structurer, someone that is better with process than people.

Argenti (2007) emphasizes that to support their leaders communicators need to become more understanding of their leaders' styles, strengths and weaknesses to give them the right kind of coaching. There's no single style of the leader, and different leaders have different styles. Also Quike (2010,4), argues that communicators are required to be experts in both their leaders' communication styles and those of employees, so that they can get the best match that would fit for both of these two. According to Clutterbuck (2001), communication professionals are often seen as assisting top management to become more effective communicator, according to Cluttebuck (2001), it is one of their hardest tasks.

Argenti (2002, p. 46), also emphasizes that the strong commitment of the CEO to the corporate communication function and the working partnerships between CEOs and directors of corporate communication can make a difference between the success and failure of the function and moreover can enhance the company's ability to obtain strategic objectives. Communication approaches that may have helped executives in good times can make things worse in bad times.

According to Mars et al., (2000) in Public listed companies the CEO is the most important spokesperson to external audience. Their most important task is to inform about the organization's strategy and its implementation. The CEO is the person that that media listens or at least is interested in her/his ideas. Therefore strategic communication of the $\mathrm{CEO}$ requires a lot of work, and training, since not only what is said but how it is said will be interpret by e.g. media. Argenti (2003) points out CEOs' vital role also in internal communication. The CEOs are the ones that are the visionaries within a company and all communications relating to organizational strategy starts with them.

Effective strategic corporate communication can be a powerful tool to counteract the relentless scrutiny and technological pounding that many businesses face today. It can function as a means of differentiation for the company and of increasing employee morale. It can take the heat out of opposition and improve the company's ability to buy supplies; take advantage of a changing situation, make a sale or gain access to market capital.
Effective corporate communication takes into account the need to capitalise on the psychology of its publics, the best mix of communication channels to suit them and minimises the likelihood of a crisis. It can also add a positive ethical layering to the organisation.

There is a strong link between communication management and strategic planning. The two should, ideally, be inseparable because communication needs to be a core organisational value which can effect change and sustain the company's vitality.

Identifying your publics in planning and evaluating programmes for strategic communication (including reputation management) it is important to identify and assess those publics which can have an influence, for good or bad, on the company. Your company does not have a single image or reputation - everyone who comes into contact with it has differing information and experiences and so differing perceptions. It is the publics who form the reputations of the company, not the company itself. Stakeholders (publics) fall into three main groups: normative, functional and diffused. Normatives include shareholders, the board, professional associations, government and provide authority and set rules. Often limits are set on the scope and conduct of the company's operations. The board of directors and the shareholders has considerable influence on what management decisions may ted.

\section{Communication And New Technology}

Communication and new Technology explores the way technology is transforming the field of communication. This new reality requires business leaders worldwide to redefine their strategies and brands in the context of digital communications platforms. Embracing social media is no longer a strategic business option, but a necessity, and a huge opportunity. Executives are in a position to emerge from the cyber jungle with renewed authority and influence. First, however, they must learn to harness the power of digital communications by integrating these tools into all business strategies, and applying them across every business function. In the new business environment, leading innovative companies are those that have successfully integrated digital communications platforms into their internal, financial, and employee communications. The companies should approach this revolution through 
International Journal of Trend in Scientific Research and Development (IJTSRD) ISSN: 2456-6470

1. Engage your customer on-line,

2. Provide digital tools for your employees

\section{Make Investor Relations more accessible}

\section{Organisational structures must evolve}

5. Move communications from the backroom to board room. In fact, at the best companies today, corporate communication is how strategy gets executed and increasingly that happens through the use of digital and social media.

The explosion of blogs, social networking sites, wikis, video sharing sites, and other powerful digital communications platforms may be the biggest gamechanger to impact business since mechanized manufacturing. In today's Web 2.0 world, company stakeholders--including employees, customers, and investors--are empowered in ways unimaginable just a few years ago, and traditional corporate hierarchies are yesterday's news. Rather than attempt to turn back the clock and reassert strict, top-down control over stakeholder relationships, the smartest companies worldwide are responding with bold new digital communications strategies based on transparency, authenticity, and inclusion, instead of secrecy, artificiality, and exclusion.

Due to new media technologies, the ubiquitous availability of information and rapid sharing of knowledge, strategic corporate communication is a complex, integrated and dynamic process (e.g .Belasen2008; Papa et al 2008). In the transactional conceptualization of communication, strategic corporate communication has been of recent interest in organizational communication. Hence, innovative concepts are needed for strategic purposes in organizational communication such as the concepts of issues management, reputation management, crisis communication, and innovation communication. One example is sensory communications a new approach to transmit information through multi- senses stimuli.

Successful strategic communication in the new media sphere cannot remain the exclusive domain of professional strategic communicators insulated from most aspects of mission execution. Technology is redefining corporate communication. Communicators who have peripheral vision and can think beyond the dots can find strategic use for the steady stream of new communication tools. Unfortunately, many in the field of communication do not see the connection between technological innovations and their role as communicators. These practitioners will have to realize that businesses are now built around information and that they must learn how to drive these technologies. Among the systems now at their disposal are the Global Positioning System, Geographical Information Systems and Management Information System. Some companies are already combining these systems, a trend that will accelerate even further if international efforts to expand openness among neighboring countries succeed.

This section presents the literature on how new technology and the Internet have influenced on communication. Also strategy communication and CEO communication are discussed in terms of current changes in the field of communication. Many companies have made enormous investments in new technology to enable both finding new ways of communicating and also spreading the message more quickly across the organization (Hartley \& Bruckmann, 2002). Teck (2006), presents that there is an emergence and rapid rise of technological innovations and social media as part of corporate communication. According to him the dynamic role of technology is a business driver and should assist corporate communication practices in stimulating strategic thinking. Whereas Goodman (2001) presents that the Internet has changed dramatically the way people in companies communicate internally and externally.

Marken (2005) argues that blogs have the potential to be an effective and efficient corporate communication tool because of the unique characteristics facilitating both one- and two-way communication, and both mass and interpersonal communication. Therefore, it is argued that blogs offer a unique channel for a corporation to directly communicate with its publics in an intimate way that resembles interpersonal communication. Cho \& Huh (2010) concluded in their study about corporate blogs as a relationship management tool that although the majority of corporate blogs seem to have features that facilitate social networking, most corporate blogs were connected rather internally to target internal stakeholders, like employees. Their findings reveal that a growing number of major corporations in the USA have adopted blogs as a corporate communication tool, although it is still a very small portion of major corporations and that most major corporations that adopted corporate blogging in 2006 
were still maintaining the practice in 2008. Teck (2006) presents that the CEO have received hardly any guidance on their role in social media, even tough with continuing technological enhancements is leading to even more flexible use of new ways in communication.

\section{Attributes of a Strategic Communication}

The term "corporate communication" embraces many aspects. According to Michael Goodman (2000), corporate communication is first and foremost "a vital management function in contemporary organizations". Goodman (2000) states that corporate communication refers to the totality of a corporation's efforts to lead, motivate, persuade, and inform its various publics, which include consumers, investors, employees, and the media. Goodman notes that "corporate communication can include such traditional disciplines as: public relations, investor relations, employee relations, community relations, media relations, labor relations, government relations, technical communication, training and employee development, marketing communication, management communication". Finally, Goodman states that corporate communication is inherently strategic in nature and offers the corporation a vital tool with which to gain a competitive advantage.

Corporate communication is the means by which a corporation is linked with the outside world. However, more than this, corporate communication has come to be the means by which much of our understanding of the world is produced. Joel Bakan (2004) has noted that over the last 150 years the corporation has risen from relative obscurity to become the world's dominant economic institution. As Bakan (2004) writes, "the corporation's dramatic rise to dominance is one of the remarkable events of modern history." The practice of strategic corporate communication has been an integral part with this rise.

The term "corporate communication" embraces many aspects. According to Michael Goodman (2000), corporate communication is first and foremost "a vital management function in contemporary organizations". Goodman (2000) states that corporate communication refers to the totality of a corporation's efforts to lead, motivate, persuade, and inform its various publics, which include consumers, investors, employees, and the media. Goodman notes that "corporate communication can include such traditional disciplines as: public relations, investor relations, employee relations, community relations, media relations, labor relations, government relations, technical communication, training and employee development, marketing communication, management communication". Finally, Goodman states that corporate communication is inherently strategic in nature and offers the corporation a vital tool with which to gain a competitive advantage.

As corporate strategy has evolved in sophistication, reliance communication should have become more fundamental--yet too often communication is nearly completely overlooked as anything more than window dressing. In fact corporate communication is the means by which a corporation is linked with the outside world. However, more than this, corporate communication has come to be the means by which much of our understanding of the world is produced. Joel Bakan (2004) has noted that over the last 150 years the corporation has risen from relative obscurity to become the world's dominant economic institution. As Bakan (2004) writes, "the corporation's dramatic rise to dominance is one of the remarkable events of modern history." The practice of strategic corporate communication has been an integral part with this rise.

Corporate communication is the means by which a corporation is linked with the outside world. However, more than this, corporate communication has come to be the means by which much of our understanding of the world is produced. Joel Bakan (2004) has noted that over the last 150 years the corporation has risen from relative obscurity to become the world's dominant economic institution. As Bakan (2004) writes, "the corporation's dramatic rise to dominance is one of the remarkable events of modern history." The practice of strategic corporate communication has been an integral part with this rise.

The link between strategy and its implementation has always been tenuous. Top consulting companies have employed countless MBAs to develop strategy for their clients. Academics at top business schools have spent their careers developing frameworks explaining how to develop better strategies for top companies. However, only a handful of academics and a cadre of tactical consultants, primarily at public relations companies, have struggled with strategy 
implementation in the area where it matters most: its communication to a set of varied constituents.

Many companies take a tactical, short-term approach to communicating with key constituencies, which is not only nonstrategic but may be inconsistent with the corporate strategy or even impede it. Exxon Corp.'s decision in 1989 to remain silent for days after the Exxon Valdez ran aground in Alaska's Prince William Sound, AT\&T Corp.'s decision to permanently lay off 40,000 employees on the first business day of 1996, a CFO's decision to avoid notifying senior managers about a downgrade of the company's stock by a major investment bank and, more recently, Merck \& Co. Inc.'s decision to wait until pressured to pull Vioxx, its arthritis and acute pain medication, from the market are all examples of communications being used tactically as part of a short-term legal or financial orientation. However, the dearth of both academic and practitioner emphasis on the strategic nature of communications, coupled with recent legal and regulatory responses to corporate scandals (such as enactment of Regulation Fair Disclosure and the Sarbanes-Oxley Act of 2002), has created a strategic communication imperative - an increasingly urgent need for executives to ensure that their communications practices contribute directly to corporate strategy implementation.

An effective communication programme incorporates the following attributes:

A company needs to demonstrate to its publics (stakeholders) that it is accountable. Strategic communications enhances the company's reputation by reflecting its performance.

$>$ In a competitive environment it is important to engender loyalty from one's customers but this must be earned by consistently effective communication. Customers support those companies they believe serve their interests via their customer-driven responses.

$>$ Strategic communication is a management function based on careful planning, research and decision-making. It must involve the organisation's goals and have measurable objectives concerning public(s) awareness, acceptance and action resulting from strategic activities.

$>$ Reputation management through strategic corporate communications must be a core value of the culture of the organisation. The communication programme requires support from the CEO and the rest of senior management in order to succeed.

$>$ There is a blurred line between entertainment and news these days, and advertising has become too expensive for many companies. More costeffective communication, rather than advertising, can take up the challenge of both issues. Marketing and public relations need to work together with equal voices. Resources are limited for many businesses so duplication of resources between these two departments must be minimised by teamwork.

New technologies such as email/internet/multimedia have provided additional tools for more varied and targeted communication.

$>$ Proactive, two-way communication between the company and its public(s) is the preferred strategy for success rather than one-way reactive methods. Strategically planned crisis communication management is a good example of this

\section{CONCLUSION \& RECOMMENDATIONS}

There is little doubt that the strategic management field will continue to grow and develop in the future. This is partially because of B-Schools requirements for graduate policy courses that generate demand for new policy area faculty (and hence facilitate entry of committed researchers into the profession). Perhaps a more important reason is the increasing corporate awareness of a messy, politicized environment in which the menu of options is both limited and complex and in which government and global competition are increasingly important forces. Since strategy's fare is complex, ill-structured problems, it is useful to cast the strategic management process as involving elements of a complex inquiry system based upon the examination of alternative perspectives and a "simulation" of entrepreneurial activity through institutionalizing the strategy-making process. Therefore, a top manager needs to first build his strategic agenda through careful inquiry and examination of his problems in terms of alternative "mixed scanning frameworks" (so called "theories").

Armed with an adequate strategic problem formulation, he can then determine the means of achieving and implementing strategic agendas by examining process aspects in terms of an organizing paradigm. That is, he should examine the degree to which his strategy choice would be consistent with the pressures of the external environment, the 
corporation's goals and resources, the risk-taking propensities of the corporation, and the culture and value systems embedded within the organization.

In a state of flux, organisations tend to overemphasise control. This is understandable, because the aforementioned highlights the integrated and coordinated roles of communication. It is of little use when the organisation integrates messages and coordinate communication without being in accordance with the overall business plan of the organisation. It seems as if the integration of managerial communication (both internal and external), marketing communication (mostly external) and public relations (mostly internal communication) are prerequisites if corporate communication is to ease the pain of change. Problems with the process of change will not disappear magically, as Argenti (1998, p. 14) puts it, but it has to be managed. People change, not organisations. Therefore people need to be informed.

Organisations must have a strategy aligned with the aims and goals of management. The corporate communication strategy should reflect the organisation's corporate strategy. Strategy formulation and strategic planning are therefore a prerequisite for the developing of a sound corporate communication strategy. The organisational strategy provides focus and direction to the communication and creates synergy between the corporate strategies and the corporate communication strategy. It is evident that little attention is paid to the corporate communication strategy, but much emphasis is placed on management strategy. Managers, however, need to use sound communication in order to inform their various publics, internally as well as externally. Since corporate communication includes all communication in the organisation, it is of paramount importance that a strategy must integrate and co-ordinate all communication.

Argenti (1998, p. 11) explains that by recognising the changing environment and adapting to it, the manager can survive the impact of change within the organisation. Various steps could be taken to ease the pain of change. Lubbe and Puth (2000, p. 62-75) propose a model for developing a corporate communication strategy. This model could be applied to manage change through corporate communication. It provides a systematic and thorough process through which all functions of corporate communication could integrate and align with organisational aims.
If corporate communication practitioners intend to gain influence in the strategic management of companies and, in consequence, contribute to good corporate governance, the following issues should first be taken into consideration:

1. Considering the gap between theoretical deliberations about strategic importance of Corporate Communications (CC) and the lack of faith of top management in $\mathrm{CC}$ practitioners, the recommendations are: (1) build corporate reputation and brand; (2) measure business outcome and predictive indicators; (3) perform boundary-spanning role strategically; (4) attract top talent with general management skills; and (5) promote symbiotic relationship with other functions.

2. Corporate communication: an integral management vision. Certainly, communication is very important in regard to its role in assessing executives in their decision-making process. As Mintzberg stated, executives spend lot of time considering the situation in the environment. They gather information about what is happening in the market, what are the main trends and challenges. That is an important part of the decision-making process. They also spend time communicating their vision, gaining influence and leadership inside and outside their companies. But this is just one part of the nature of corporate communication. Corporate communication comprises a structure and professionals whose function is to organise communication relationships throughout the company and outside it. The structural dimension is, in this respect, an important feature. It helps to hold communication relationships together, giving coherence and consistency.

3. Concerning the existence of various stakeholders and relationships that the company has to deal with, there is some evidence, from both theoretical and empirical points of view, that the profession tends to coordinate diverse stakeholder communication relationships. However, a significant question arises in this regard: how are such different information demands to be managed? The structural dimension appears again as an important topic. Empirical evidence in the Spanish market, in line with literature and the international state of affairs, seems to draw attention to the need to coordinate different stakeholder relationships. This situation requires 
International Journal of Trend in Scientific Research and Development (IJTSRD) ISSN: 2456-6470

that diversity be a factor in the management of communication, but that the management approach should also be a consistent one. Only if there is a professional in charge of the coordination of different communication programs can a company's various communication activities be coherent.

4. Aligning strategic goals with communication goals. Communication goes with business; it manages the corporate story (Holten Larse, 2000). Practitioners help to shape the reality of the company. Company and stakeholders share a common public sphere. The company's success depends, as a result, on adjustment to the expectation and demands of publics, not only in commercial sense.

5. Relating to previous comments, good corporate governance requires the management of complex elements and, in the end, exact knowledge about what is taking place in the environment. Communication managers become a catalyst that enables company executives to take stakeholder demands into account and adapt company service to its publics. That situation cannot address without coordinated communication relationships.

6. The corporate communication function is still no institutionalized, and it can be stated that its contribution to corporate governance is limited. There are some significant reasons why this contribution is regarded as limited: firstly, if communication managers do not usually participate in the executive team, it is difficult to participate in corporate governance. Secondly, which follows from the previous one communication practitioners still do not have influence on the strategic decision-making process? For this reason, it would seem to be very difficult to translate stakeholder demands and influence executive decisions.

7. Notwithstanding the considerations above, it may be concluded that the profession is conceiving what its strategic function for organisations and company may be. The increasing role of communication managers within companies suggests that company executives tend to regard communication as an important function.

Further research is necessary: in theoretical terms because a deeper understanding of the value communication may have for good corporate governance is required. Empirical research must also be carried out to know if the trend in the profession is to gain influence on executive teams and, especially, whether communication practitioners influence the way companies are managed.

\section{REFERENCES}

1) Åberg, L. (2006). Johtamisviestintää! Esimiehen ja asiantuntijan viestintäkirja. Jyväskylä: Inforviestintä.

2) Argenti,P.A. (1998) ."Communication in management, Communication in organizations", Irwin / McGraw Hill (Boston)

3) Argenti, P.A. (2007), Corporate Communication $\left(4^{\text {th }}\right.$ ed). New York: Mc-Graw Hill

4) Argenti P.A. (2009) Strategic Corporate Communication. A Global Approach for Doing Business in the New India, New York: Mc Graw.

5) Argenti, P \& Forman, J. (2002). The Power of Corporate Communication. New York,NY: McGraw - Hill.

6) Argenti, P. (2003). Corporate communication. 3rdedition. New York: The McGraw -Hill Companies

7) Belasen, A.T. (2008). The Theory and Practice of Corporate Communication. A Competing Values Perspective. Thousand Oaks,C.A.:Sage

8) Cho, S. \& Huh, J. (2010). Content analysis of corporate blogs as a relationship management tool. Corporate Communications: An International Journal, 15(1), 30-48.

9) Clutterbuck, D. (2001). The communicating company. Journal of Communication Management, 6 (1), 70-77.

10) Cornelissen, J. (2008). Corporate communication - A guide to theory and practice. $2^{\text {nd }}$ edition. Thousand Oaks, CA: Sage Publications Inc.

11) Chandler, A. D. 1962. Strategy and structure. Cambridge, MA: MIT Press

12) Demont-Lugol, L., Kempf, A., Rapidel, M. and Scibetta, C. 2008. Communication des entreprises: stratégies et pratiques. 2nd ed. Paris: Armand Colin.

13) DRUCKER, P.F. 1988. In Kotler, P, Marketing management. Sixth edition. Englewood Cliffs, New Jersey: Prentice Hall International Inc.

14) Elisa Juholin, (2001) "Image or substance? Candidate or campaign? A case study of a presidential election campaign in Finland", Corporate Communications: An International Journal, Vol. 6 Iss: 3, pp.124 - 131

15) Frigo M \& Litman, J. (2001). What is strategic management? Strategic Finance. 83 (6), 8-12. 
International Journal of Trend in Scientific Research and Development (IJTSRD) ISSN: 2456-6470

16) Forceville, Charles (2009). "The role of nonverbal sound and music in multimodal metaphor."

17) Grunig, J. E. (1989). Symmetrical presuppositions as a framework for public relations theory. In C. H. Botan \& V. Hazelton (Eds.), Public relations theory (pp. 17-44). Hillsdale, NJ: Lawrence Earlbaum, Assoc.

18) Goodman, M. (2001). Current trends in corporate communication. Corporate Communications: An International Journal, 6 (3), 117-123.

19) Hartley, P. \& Bruckmann, C. (2002). Business Communication. London: Routledge.

20) Harvey, M.S. 2002. The first Old World species of Phrynidae (Amblypygi): Phrynus exsul from Indonesia. Journal of Arachnology. In press.

21) Hämäläinen, Virpi \& Maula, Hanna 2004. Strategiaviestintä. Inforviesitntä Oy. Helsinki.

22) Holten Larsen ,Oxford University Press; 2000; ISBN 0-19-829778-5;

23) Johnson, G. (2009). Fundamentals of strategy.London: Prentice Hall, FT

24) TNCs: 'institutional psychopaths' - Joel Bakan (2004)

25) Kalla, H. (2006). Integrated Internal Communications in the Multinational Corporation. Helsinki School of Economics Dissertation. A-280. HeSE Print, Helsinki.

26) Kameda, T. 2005. The robust beauty of majority rules in group decisions. In Psychological Review, Vol. 112, no. 2, 494-508.

27) Lamar Reinsch Jr, N. (2009). Management Communication. In Bargiela-Chiappini, F.(Ed.), The Handbook of Business Discourse (pp. 279 290). Edinburgh: Edinburgh University Press.

28) Louhiala-Salminen, Leena (1999). Was there life before them: fax and e-mail in business communication. From correspondence to messages: a genre approach (95-97). Jyväskylä: Jyväskylä UP.

29) Louhiala-Salminen, L: (2009). Disciplinary Perspectives: Business Communication in $\mathrm{F}$. Bargiela-Chiappini(ed), The Handbook of Business Discourse (pp .305-316), Edinburgh: EUP.

30) Lubbe, B. \& Puth, G. 2000. Public Relations in South Africa : a Management Reader, Sandown:. Heinemann:

31) Mars, M. \& Virtanen, M. \& Virtanen, O. (2000). Sijoittajaviestintä strategisena työkaluna. Helsinki: Edita.
32) Miller, K. (1996). Who are we and what are we doing? Management Communication Quarterly : $M c Q, 10$ (1), 3-5.

33) Mills, R. (1991). A new understanding of self: The role of affect, state of mind, selfunderstanding, and intrinsic motivation. Journal of Experimental Education, 60(1), 67-81.

34) Mintzberg, H. (1979), 'Patterns is strategy formation', International Studies of Management and Organisation IX(3), 67-86.

35) Oliver, S. 2007. Public Relations Strategy. 2nd ed. London: Kogan Page.

36) Papa, M.J. Daniels, T.D. \& Spiker. B.K. (2008). Organisational Communication. Perspective and Trends. Thousand Oaks, C.A. Sage

37) Porter, M. (1997). Creating tomorrow's advantages. In Gibson, R., Rethinking the future. London: Nicholas Brealey Publishing.

38) Quirke, B. (2010). Steering leaders out of a crisis using effective communication. Strategic Communication Management, 14( 1) 4-24

39) Quike Navarro House Violin Session in Andiamo Di La, Valladolid. January 9Th, 2010.

40) Reinsch, N.L.. "Management Communication." Handbook of Business Discourse. Ed. BargielaChiappini. Edinburgh, UK: University of Edinburgh Press, 2009: 279-291

41) Robert Harris: Evaluating Internet Research Sources. Southern California College. Version Date: November 17, 1997.

42) STEYN, B. 2000. Corporate communication strategy-Missing link between corporate strategy and communication function. Paper delivered at the Communication 2000 (SACOMM) Conference at the University of Pretoria, 5 May.

43) Suominen, K. \& Karkulehto, K. \& Sipponen, J. \& Hämäläinen, V. (2009). Esimies strategiavaikuttajaksi. Juva: WSOYpro Oy

44) Steyn, B. (2003). From strategy to corporate communication strategy: A conceptualisation. Journal of Communication Management, 8 (2), 168-183.

45) Steyn, B. (2000a). Strategic management roles of the corporate communication function. Researchscript in partial fulfilment of the requirements for a lectured masters degree in Communication Management. University of Pretoria, 30 June.

46) Teck, F. (2006). Competitive aesthetics, semiotics, chaos and leadership: Corporate photography strategy for the CEO. Corporate Communications, 11( 2), 109-126. 
47) TIBBLE, S. 1997. Developing communications strategy. Journal of Communication Management, 1(4):356- 361.

48) Van Riel, C. B. M. (1995). Principles of corporate communication. London: Prentice Hall.

49) Walker, R. (2006). Strategic Business Communication. Thomson: South-Western

50) Weber, Max (1947 Max Weber: The Theory of Social and Economic Organization. Translated by A. M. Henderson \& Talcott Parsons. NY: The Free Press.

51) Westphslen, M.H., 2004. Communication, $4^{\text {th }}$ edition p.67

52) Winner, P (1993) Effective Public Relations Management, Kogan Page, London 